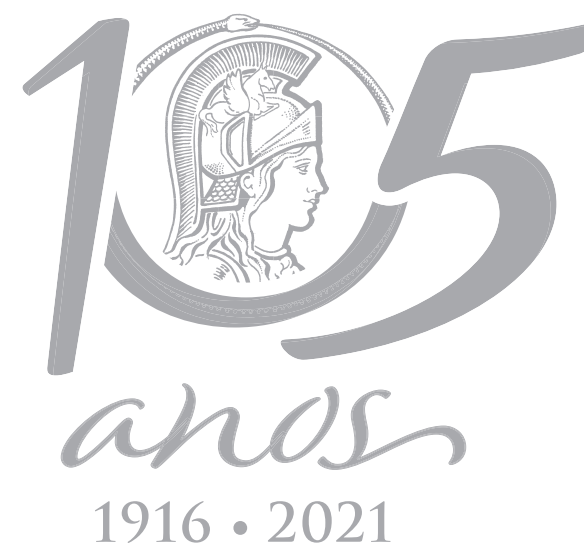

\title{
ECOSYSTEMS
}

\section{A Method to Assess the Risk of Sun Coral Invasion in Marine Protected Areas}

\author{
THIAGO D.T.C. COUTO, ELIANNE P. OMENA, SIMONE S. OIGMAN-PSZCZOL \& \\ ANDREA O.R. JUNQUEIRA
}

\begin{abstract}
The safest and most efficient method of avoiding costs and impacts associated with biological invasions is to prevent the introduction and establishment of non-native species. In Brazil, two invasive coral species have been causing ecological, economic and social impacts: Tubastraea coccinea and Tubastraea tagusensis. This work presents a protocol to analyze the risk of invasion in Marine Protected Areas (MPAs) in the State of Rio de Janeiro considering the main vector of these species on the Brazilian coast. This protocol takes five risk factors into account: environmental similarity between the donor area and the possible receiving area; available substrate for colonization; proximity to the donor region; proximity and quantity of oil platforms and drill ships that passed by the analyzed MPAs and proximity and quantity of oil platforms and drill ships that anchored near the MPAs. Results must be used by decision-makers for a better management of Marine Protected Areas. The protocol we present can be applied to analyze the relative risk of invasion throughout the Brazilian coast, in order to prioritize areas for early detection and monitoring of the presence of sun corals.
\end{abstract}

Key words: anchored vessels, biofouling, bioinvasion, donor area, drill ships, oil platforms.

\section{INTRODUCTION}

Thousands of species have been carried by man from their native ranges during the last centuries impacting many marine ecosystems around the world (Lockwood et al. 2007). Invasive species can impact ecosystems negatively, resulting in loss of biodiversity, loss of native and commercial species, and changes in the function and structure of communities and ecosystems (Mack et al. 2000), which can also cause social and economic impacts. Shipping is the main global pathway for unintentional transference of marine non-indigenous species (Molnar et al. 2008). Considering this pathway, hull fouling is one of the main vectors for the introduction of alien species (Hewitt et al. 1999), as shown in Brazil by Ferreira et al. (2006) and Farrapeira et al. (2011). Bioinvasion can occur through primary introduction, when a non-native species arrives for the first time and through secondary introduction when it spreads from this point by anthropic or natural means (Olenin et al. 2011).

"Sun coral" is the popular name given to species of the genus Tubastraea. Two species of sun coral are found on the Brazilian coast, Tubastraea coccinea (Lesson 1829) and Tubastraea tagusensis (Wells 1982) and have been causing ecological, economic and social impacts. Both species are native to the Pacific Ocean and, besides Brazil; they have invaded the Caribbean, the Gulf of Mexico (Sammarco et al. 2004, Figueroa et al. 2019) and the Canary Islands (López et al. 2019).

The negative impacts caused by these invasive species were shown by many studies. 
For example: competition for space with native species (Lages et al. 2010, 2011, 2012, Santos et al. 2013), mortality of native coral species (Miranda et al. 2016a), changes in benthic (Lages et al. 2011, De Paula et al. 2017, Silva et al. 2019) and nektonic community structure and functioning (Miranda et al. 2018), and impact on fisheries resources such as commercial mussels (Mantelatto \& Creed 2015).

Corals of the genus Tubastraea are azooxanthellate and were first reported in Brazil in the 1980s as fouling organisms on oil and gas platforms in the Campos Oil Basin, in the State of Rio de Janeiro (Castro \& Pires 2001). At the end of the 1990s sun corals began to invade native communities on rocky shores at Itha Grande Bay, State of Rio de Janeiro, a region considered to be a marine biodiversity hot spot in Brazil (Creed et al. 2007) that houses part of the Tamoios Marine Protected Area. The region has movements of oil platforms and other vessels due to the presence of two ports, an oil terminal, shipyards and an anchorage. The latter is the probable first point of the introduction on the Brazilian coast (Silva et al. 2014). Currently sun corals occur in coastal municipalities, mobile artificial structures and shipwrecks along more than 3,500 km of the Brazilian coastline (Creed et al. 2017a). Bioinvasion of sun corals in Brazil is now considered a major threat to marine biodiversity and has led the national government to plan control and management policies on the Brazilian coast. A national prevention plan with a legal framework applicable to the management of sun coral, including risk analysis, has recently been published by the National Biodiversity Committee (CONABIO 2018).

There are several pieces of evidence that the biofouling on oil platforms and/or drill ships is the main vector of introduction of sun coral on the Brazilian coast, as 1) the oldest records of sun coral in Brazil are on oil platforms; 2) there was a link between the oil and gas transportation by navigation and the records of the invasions in natural communities; 3 ) the main points of the coastal introduction are always associated with port facilities used by the oil and gas industry (Creed et al. 2017a). Recently, stronger evidence of the role of these vectors for sun coral invasion was found by molecular studies by Capel et al. 2019. They found a higher diversity of multi-locus genotypes (MLGS) on vectors than at invaded sites suggesting that vectors were contaminated before they entered the Southwestern Atlantic. Their research indicates a high prevalence of clonality at the invaded sites and the occurrence of multiple invasions and also secondary invasions along the coast. Although they are not the main vectors, sun corals could be introduced by marine litter (Mantelatto et al. 2020).

Kaplan and Garrick (1981) define risk as the probability of occurrence of an undesired event, along with some evaluation of the consequences of the event. Traditional risk assessment provides an evaluation of the likelihood and consequences of adverse ecological effects as a result of exposure to one or more stressors (Gentile et al. 1993). Risk assessment for marine bioinvasion provides a tool to aid managers in controlling and reducing the rate of current invasions and to prevent new invasions. Risk assessment characterizes the likelihood and severity of potential adverse effects of exposure to hazardous agents or activity (i.e., stressors). Risk management is the process of identifying, evaluating, selecting, and implementing actions to reduce risk (Andersen et al. 2004).

In Brazil, T. tagusensis and T. coccinea were introduced simultaneously (Creed et al. 2017a). They often co-occur and sometimes their colonies are physically intertwined (Paula et al. 2014). T. tagusensis has a slightly larger range and is more abundant than $T$. coccinea at Ilha Grande Bay (Silva et al. 2014). However, 
in a number of comparative studies, the two species presented only small differences related to substrate preference and period of sexual maturation (Paula et al. 2014). Also, in many published surveys there is no distinction between the distributions of both species on the Brazilian coast (eg. Sampaio et al. 2012, Miranda et al. 2016b). A very recent study (Figueroa et al. 2019) recorded the presence of $T$. tagusensis for the first time in the Gulf of Mexico and the authors state that, due to the cryptic nature of these two species, it is possible that previous studies confused the two species at the time of identification. For these reasons, it might be more prudent to evaluate their risk together.

Marine Protected Areas (hereafter denoted as 'MPAs') were prioritized in the present study because they are key to replenishing biodiversity and nourishing the growing human population. In Rio de Janeiro, the MPAs often include mangroves and mainly rocky shores, which play an important role as nursery areas and provide ecosystems services such as coastal protection. MPAs also generate opportunities for tourism, which in turn brings jobs and income.

Preventing the introduction and establishment of nonindigenous species is the safest and most efficient way to avoid the costs and impacts associated with biological invasions (Marchetti et al. 2004). This work presents a risk analysis protocol of sun coral introduction in marine protected areas in the State of Rio de Janeiro. Almost all the MPAs in Rio de Janeiro that have rocky shores are invaded by suncorals. However, there are locations inside the contaminated MPAs, like several islands, that do not have sun coral yet. So, the endpoint of this risk analysis is to prevent further introductions to areas that are not invaded yet and also to less infested areas that could be managed in Rio the Janeiro State. With this protocol it will be possible to establish which area requires more attention to prevent primary and/or secondary introductions. Moreover, the protocol can be extended for risk assessment analysis in other areas which present risk of bioinvasion species that have biofouling as the main vector of invasion. This work could provide important data for government sectors that are responsible for the implementation of the "National Plan for Prevention, Control and Monitoring of Sun Corals (Tubastraea spp.)".

\section{MATERIALS AND METHODS}

Marine Protected Areas which have rocky shores within the limits of the conservation unit were chosen to perform the risk analysis. Six MPAs were used in the risk analysis, one of which (Tamoios MPA) was considered donor area because it is one of the most invaded sites in Brazil. All MPAs that have rocky shores inside their limits in Rio de Janeiro are contaminated with sun corals. For this reason, in order to test the protocol, we assumed that only Tamoios MPA is contaminated with sun coral. The relative risk of sun coral invasions was assessed for the other five Marine Protected Areas from the south to the north of the State of Rio de Janeiro (Figure 1).

This protocol was based on the Ballast Water Risk Assessment (Clarke et al. 2004), applied by the Global Ballast Water Management Programme (GloBallast), implemented by the International Maritime Organization. GloBallast assessed the risk of bioinvasion related to ballast water. Our research used a different approach assessing the risk related to fouling species. Some of the factors used in this work were very similar to some factors used in the GloBallast, such as environmental similarity and the total number of ballast water discharges that here is represented by the quantity of 

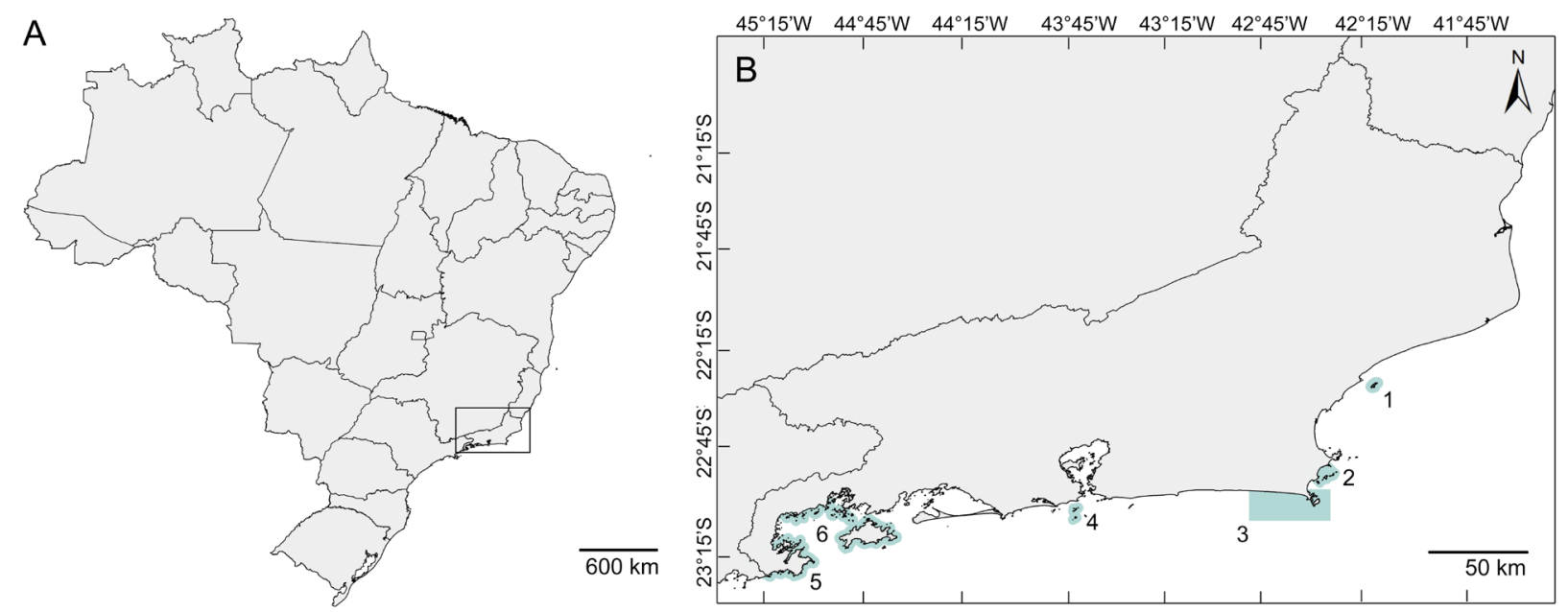

Figure 1. a) Brazil; b) Location of the analyzed MPAs in Rio de Janeiro State. 1-Santana MPA; 2-Pau-Brasil MPA; 3-Arraial do Cabo MPA; 4-Cagarras MPA; 5-Cairuçu MPA; 6-Tamoios MPA (donor area).

platforms and drill ships. However, other factors were included focusing on different types of organisms and vectors. The major difference between this method and the GloBallast method is the factor related to species that present risk of bioinvasion, that was used in the GloBallast method but not in this study, since here only risk of invasion by sun corals was analyzed.

This protocol considers five risk factors: I) Environmental similarity between the donor area and the possible receiving area; II) available substrate for sun coral colonization; III) proximity to the donor region; IV) proximity and quantity of oil platforms and drill ships that passed by the analyzed MPA; V) proximity and quantity of oil platforms and drill ships that anchored near the marine protected areas. In order to have all risk factors on the same scale, they were standardized between 0 and 1 . This process allow us to compare scores between different types of variables

\section{Marine Protected Areas}

In this study, five marine protected areas were assessed, three of them located on the northeast coast (Santana MPA, Pau-Brasil MPA and Arraial do (abo MPA), one placed at the city of Rio de Janeiro (Cagarras MPA) and one along the south coast (Cairuçu MPA). The MPA that was considered as donor area (Tamoios MPA) is also located along the south coast.

The Santana Archipelago MPA is located 8 $\mathrm{km}$ from the Macaé city coast which has onshore installations for oil and natural gas exploration and production from the Campos Basin. The PauBrasil MPA and Arraial do Cabo MPA were under influence of the main coastal upwelling system in Brazil (Coelho-Souza et al. 2012). These areas are composed of a narrow continental zone, small islands and a great marine extension. The Cagarras Islands MPA is composed of six islands located near Rio de Janeiro city, and heavily affected by urban development. The Cairuçu MPA and Tamoios MPA are both located in Itha Grande Bay. The Cairuçu MPA is composed of 63 islands in the municipalities of Paraty. It stretches from Ponta de Trindade to Saco de Tarituba. The insular part of the Tamoios MPA consists of approximately 100 islands including Ilha Grande and all other islands that are part of the municipality of Angra dos Reis. Tubastraea coccinea and $T$. tagusensis are considered pest corals in that region and occur in high abundance on several rocky shores, spreading with a rate of 
$2.1 \mathrm{~km}$ per year (Silva et al. 2014). This MPA which overlaps with the Ecological Station of Tamoios and Ilha Grande Natural Park) is one of the most invaded sites in Brazil and for that reason was considered as the donor area. The other five MPAs were analyzed in relation (similarity and distance) to the Tamoios MPA.

\section{Environmental Similarity Analysis}

The more a system is environmentally similar to the donor area, the greater is the risk of a successful establishment of the target species. So, it is important to know the similarity between each analyzed MPAs and the donor area (Tamoios MPA). The Euclidian distance was calculated with the abiotic factors shown in Table I using PRIMER 6.0 software. Minimal, maximal and average temperature, salinity, dissolved nitrate, dissolved phosphate, dissolved oxygen and chlorophyll concentration were gathered from the National Oceanic and Atmospheric Administration (NOAA 2017) website of the Department of Commerce of the United States, through the NOAA View Global Data Explorer. Through this website, NOAA makes available environmental data from different sources. The data of salinity, nitrate, phosphate and oxygen are available for the year of 2013. For temperature and chlorophyll was gathered the data from June of 2015 until July of 2017. All environmental data used in the environmental similarity were gathered in a month basis. Precipitation data were gathered from the website of the Brazilian National Institute of Meteorology (INMET 2017 - Instituto Nacional de Meteorologia) and the maximum tidal range data was provided by the Brazilian Navy through the Hydrography and Navigation Directorate website (DHN 2017 - Departamento de Hidrografia e Navegação).

The Euclidian distance results show dissimilarities, so, in order to transform these values into similarity values, the expression 1/1-x (Johnson \& Wichern 1988) was used, where $x$ is the value to be transformed. The new values will range between 0 and 1 , with 0 representing the maximum difference and 1 the maximum similarity. The greater the similarity with the donor area is, the greater is the risk of sun coral establishment.

\section{Available Substrate to Sun Coral Colonization}

The quantity of available substrate is important to sun coral risk analyses because these corals do not settle in non-consolidated substrates. Therefore, the smaller the quantity of rocky shore in each MPA, the lower will be the risk of sun corals to settle in that area. A model never contains all the features of the real system, because then it would be the real system itself (Jørgensen \& Bendoricchio 2001) and for this reason, we have to work with some level

Table I. Abiotic factors used in the multivariate similarity analysis using Euclidian distance.

\begin{tabular}{|c|c|}
\hline $\begin{array}{c}\text { Minimum Temperature } \\
\left({ }^{\circ} \mathrm{C}\right)\end{array}$ & $\begin{array}{l}\text { Average Dissolved } \\
\text { Phosphate }(\mu \mathrm{m} / \mathrm{l})\end{array}$ \\
\hline $\begin{array}{c}\text { Maximum Temperature } \\
\left({ }^{\circ} \mathrm{C}\right)\end{array}$ & $\begin{array}{l}\text { Minimum Dissolved } \\
\text { Oxygen }(\mathrm{ml} / \mathrm{l})\end{array}$ \\
\hline $\begin{array}{c}\text { Average Temperature } \\
\left({ }^{\circ} \mathrm{C}\right)\end{array}$ & $\begin{array}{l}\text { Maximum Dissolved } \\
\text { Oxygen }(\mathrm{ml} / \mathrm{l})\end{array}$ \\
\hline Minimum Salinity & $\begin{array}{l}\text { Average Dissolved } \\
\text { Oxygen }(\mathrm{ml} / \mathrm{l})\end{array}$ \\
\hline Maximum Salinity & $\begin{array}{l}\text { Minimum Chlorophyl } \\
\text { Concentration }(\mathrm{ml} / \mathrm{l})\end{array}$ \\
\hline Average Salinity & $\begin{array}{l}\text { Maximum Chlorophyl } \\
\text { Concentration }(\mathrm{ml} / \mathrm{l})\end{array}$ \\
\hline $\begin{array}{c}\text { Minimum Dissolved } \\
\text { Nitrate }(\mu \mathrm{m} / \mathrm{l})\end{array}$ & $\begin{array}{l}\text { Average Chlorophyl } \\
\text { Concentration }(\mathrm{ml} / \mathrm{l})\end{array}$ \\
\hline $\begin{array}{c}\text { Maximum Dissolved } \\
\text { Nitrate }(\mu \mathrm{m} / \mathrm{l})\end{array}$ & $\begin{array}{l}\text { Total precipitation of the } \\
6 \text { more dry months }(\mathrm{mm})\end{array}$ \\
\hline $\begin{array}{c}\text { Average Dissolved Nitrate } \\
(\mu \mathrm{m} / \mathrm{l})\end{array}$ & $\begin{array}{l}\text { Total precipitation of the } \\
6 \text { more wet months }(\mathrm{mm})\end{array}$ \\
\hline $\begin{array}{l}\text { Minimum Dissolved } \\
\text { Phosphate }(\mu \mathrm{m} / \mathrm{l})\end{array}$ & $\begin{array}{l}\text { Maximum Tidal } \\
\text { Amplitude (m) }\end{array}$ \\
\hline $\begin{array}{l}\text { Maximum Dissolved } \\
\text { Phosphate }(\mu \mathrm{m} / \mathrm{l})\end{array}$ & \\
\hline
\end{tabular}


of uncertainties (Treut 1999). Faced with the impossibility to know the depth of every point of every substrate analyzed, it was assumed that the entire extent of available substrate measured reaches the same depth.

Through the software Google Earth Pro, the surface extension of the rocky shores in each analyzed MPA was measured and was divided by the total coastal extension of the Rio de Janeiro State $(636 \mathrm{~km})$, resulting in values between 0 and 1.

\section{Proximity to the Donor Area}

The proximity to an invaded area increases the chance of new invasions. An area that is located closer to the donor area has a higher risk of sun coral invasion, because this species has exponential propagule dispersal, with higher quantities settling at shorter distances. In order to analyze the risk in relation to the proximity of the donor region, three classes were selected. Zilberberg et al. (2016) shows that, in Bahia coast, the larvae of the species of the genus Mussismilia, depending on the season of the year, specially wind intensity and duration, could reach between $30 \mathrm{~km}$ and $100 \mathrm{~km}$ distance. The species of the genus Mussismilia frequently cooccurs in the same places that the sun corals species along the Brazilian coast. Because of a lack of data on larval dispersal of both sun coral species, the maximum reach of larvae of species of the genus Mussismilia (100 km) (Zilberberg et al. 2016), was used as a proxy. In order to relativize the risk, the maximum distance reached by the larva was divided into three ranges. To ensure greater protection of the coast biodiversity, the closest range $(0-40 \mathrm{~km})$ is $10 \mathrm{~km}$ bigger than the other two (40-70 km and $70-100 \mathrm{~km})$. If a MPA is located up to $40 \mathrm{~km}$ from the Tamoios MPA, it received the score 1. If the distance is between 40 $\mathrm{km}-70 \mathrm{~km}$, the score 0.1 was given and between $70 \mathrm{~km}-100 \mathrm{~km}$, the score 0.01. If the analyzed area is located at a distance over $100 \mathrm{~km}$, it was assumed to have no risk of sun coral invasion through natural larval dispersal. The choices for score values are related to the settlement behavior of sun coral larvae. Although they can live for 18 days in an aquarium without settling (Paula et al. 2014); they usually settle quickly near parental colonies (Creed et al. 2017a). We assume that this fact implies a higher propagule pressure closer to the parental colonies (sources of propagule) and an exponential decrease at greater distances.

\section{Oil Platforms and Drill Ships}

Oil platforms and drill ships are the main vectors of sun coral introduction in Brazil (Creed et al. 2017a). It was essential to develop a risk assessment based on these types of structures. This factor has no relation to the donor area. We applied a precautionary approach considering that all platforms and drill ships on the Brazilian coast are infested with sun coral. This was assumed because there is a lack of information about the time that a platform or drill ship has been out of dry dock (or offa heavy lift ship) and of information about all the places that the vessels anchored since it was in operation. Recently, there has been progress in the global tracking of ship journeys. The Automatic Identification System (AIS), mandatory on cargo ships engaged in international voyages, automatically reports approaching ships to coastal stations (Seebens et al. 2013). The Brazilian Navy has AIS information and provided the data for the accomplishment of this project. Data were collected from all platforms and drill ships registered in the Rio de Janeiro coastal area from June of 2015 until July of 2017, corresponding to two years or 730 days of data. Using the AIS data and the Google Earth software, platform routes were followed and the distances from the coast were measured. 


\section{Non-Anchored Oil Platforms and Drill Ships}

Analyzing the AIS data in Google Earth, it is possible to know the platforms that did not anchor close to a MPA under risk analysis. It is important to know that the same platform and/ or drill ship could be considered "anchored" or "non-anchored" depending on the MPA under analysis. The platforms were divided in three different categories and to obtain a score for this risk factor, a weighted average was calculated (equation 1). The criterion used to give the weights to the different distances of the platforms and drill ships from each MPA, takes the exponential propagule dispersion of both sun coral species into account. For this reason, higher weights were given to the closest distances analyzed and lower weights to the farthest distances analyzed. The denominator in the formula (111) represents the sum of the weights.

Sun coral larvae tend to settle near to the mother colony (Creed et al. 2017a). However, some larvae could be transported far from the original point.

$\frac{[((A / Y) \times 100)+((B / Y) \times 10)+((C / Y) \times 1)]}{111} \quad$ Equation 1

Where: $Y$ is the total number of platforms and drill ships that passed by the Rio de Janeiro State coast at a maximum distance of $100 \mathrm{~km}$. A is the number of platforms and drill ships that traveled between 0-40 km from the analyzed MPA. $B$ is the number of platforms and drill ships that went by between $40 \mathrm{~km}-70 \mathrm{~km}$ from the analyzed MPA and $C$ the number of platforms and drill ships that went by between $70 \mathrm{~km}-100$ $\mathrm{km}$ from the analyzed MPA. Platforms and drill ships that passed at more than a $100 \mathrm{~km}$ from the coast were considered to offer no risk of sun coral invasion.

\section{Anchored Oil Platforms and Drill Ships}

With the AIS data it is also possible to estimate the quantity of days that a platform remains anchored. In this section, besides the distance that each platform anchored from the MPA, the anchorage time was also considered. Therefore, equation 2 was used to obtain the score for this section.

The quantity of days that a platform remains anchored is important for the risk analysis. The greater is the number of days that the vessel has been anchored, the greater is the risk. The maximum anchorage time was calculated taking into account the platform and drill ships that has spent more time anchored at each analyzed distance.

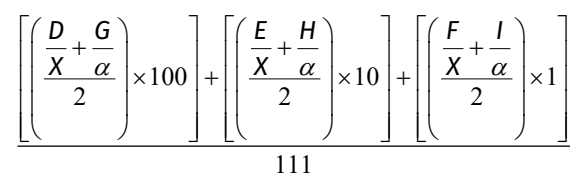

Equation 2

$X$ is the total number of platforms and drill ships that anchored within $100 \mathrm{~km}$ from Rio de Janeiro State coast. $D$ is the number of platforms and drill ships that anchored between 0-40 $\mathrm{km}$ from each MPA coast. $\mathrm{E}$ is the number of platforms that anchored between $40 \mathrm{~km}-70 \mathrm{~km}$ from each MPA coast and $F$ is the number of platforms that anchored between $70 \mathrm{~km}-100 \mathrm{~km}$ from each MPA coast. Platforms and drill ships that anchored at more than $100 \mathrm{~km}$ from the coast were considered to offer no risk of sun coral invasion.

$\alpha$ is the period of study, in days, which in this case is 730 . $G$ is the maximum number of days that a platform and/or drill ship had been anchored between 0-40 km during this period of study from each MPA. $H$ is the maximum number of days that a platform and/or drill ship remained anchored between $40 \mathrm{~km}-70 \mathrm{~km}$ during this period of study from each MPA. I is the maximum number of days that a platform and/or drill ship had been anchored between 0-40 km during this period of study from each MPA. 


\section{RESULTS}

\section{Environmental Similarity}

Similarity between the donor region Tamoios MPA and each of the other analyzed Marine Protected Areas was calculated. Cairuçu MPA was the region most similar to the donor area (Table II). The differences between the similarity scores of Santana, Cagarras, Arraial do Cabo and Pau-Brasil MPAs were not high, the minimum being 0.63 to Pau-Brasil MPA and Arraial do Cabo MPA. As the environmental similarity was high for all the MPAs, showing that the similarity does not influence in the sun coral invasion in Rio de Janeiro State, the environmental similarity factor was then removed from this risk analysis.

\section{Available Substrate to Sun Coral Colonization}

Table II shows the available substrate scores for the MPAs. Cairuçu was the MPA that presented the highest risk concerning the available substrate because this region has the highest extension of rocky shore values (Table III). Arraial do Cabo MPA was in the second position, but rocky shore extension of this area is less than a quarter of Cairuçu MPA. In general, the score of Cairuçu MPA was considerably higher (more than 5 times) than the other MPA scores.

\section{Proximity to the Donor Area}

Cairuçu and Tamoios MPAs are both located inside the Ilha Grande Bay, which explains the highest score of Cairuçu MPA for the factor "proximity to the donor area" (Table II). The other MPA that have a score in this section was Cagarras MPA, which is located between 70 $\mathrm{km}$ and $100 \mathrm{~km}$ from Tamoios MPA. Arraial do Cabo MPA, Pau-Brasil MPA and Santana MPA are located more than $100 \mathrm{~km}$ from the donor area, receiving the score 0 .
Table II. Results for all the analyzed factors and environmental similarity. ES: environmental similarity between the analyzed MPAs and the donor area; AS: available substrate; P: proximity to the donor area; NAPD: non-anchored platforms and drill ships; APD: anchored platforms and drill ships.

\begin{tabular}{|c|c|c|c|c|c|}
\hline $\begin{array}{c}\text { Marine } \\
\text { Protected } \\
\text { Areas }\end{array}$ & ES & AS & P & NAPD & APD \\
\hline Cairuçu MPA & 1 & 0.31 & 1 & 0.08 & 0.17 \\
\hline Cagarras MPA & 0.72 & 0.02 & 0.01 & 0.38 & 0.36 \\
\hline Santana MPA & 0.78 & 0.01 & 0 & 0.12 & 0.27 \\
\hline Arraial do Cabo & 0.63 & 0.06 & 0 & 0.01 & 0.03 \\
\hline MPA & 0.63 & 0.06 & 0 & 0.27 & 0.03 \\
\hline Pau-Brasil MPA & & & & \\
\hline
\end{tabular}

Table III. Rocky shores extension for all the analyzed Marine Protected Areas.

\begin{tabular}{|c|c|}
\hline Marine Protected Areas & Rocky Shore Extensions \\
\hline Cairuçu MPA & $202.8 \mathrm{~km}$ \\
\hline Arraial do Cabo MPA & $41.5 \mathrm{~km}$ \\
\hline Pau-Brasil MPA & $39.1 \mathrm{~km}$ \\
\hline Cagarras MPA & $13.8 \mathrm{~km}$ \\
\hline Santana MPA & $11.7 \mathrm{~km}$ \\
\hline
\end{tabular}

\section{Oil Platforms and Drill Ships}

The Brazilian Navy tracked all oil platforms and drill ships off the coast of Rio de Janeiro State, resulting in a total of 75 oil platforms and drill ships that were recorded in both years. From the total, 31 platforms were considered as nonanchored oil platforms and drill ships and 41 as anchored oil platforms and drill ships. The number of anchored and non-anchored oil platforms and drill ships is presented for each analyzed distance and MPA (Table IV).

\section{Non-anchored Oil Platforms and Drill Ships}

A total of 31 platforms and drill ships were classified as non-anchored. Arraial do Cabo was the MPA that had more platforms and drill ships 
Table IV. Number of non-anchored and anchored oil platforms and drill ships for each analyzed distance and MPA.

\begin{tabular}{|c|c|c|c|c|c|}
\hline \multicolumn{6}{|c|}{ Non-anchored } \\
\hline Distance & Santana MPA & Pau-Brasil MPA & Arraial MPA & Cagarras MPA & Cairuçu MPA \\
\hline $0-40 \mathrm{~km}$ & 4 & 9 & 10 & 13 & 3 \\
\hline 40-70 km & 3 & 6 & 6 & 1 & \\
\hline 70-100 km & 11 & 2 & 8 & 1 & \\
\hline Total & 18 & 17 & 24 & 15 & 3 \\
\hline \multicolumn{6}{|c|}{ Anchored } \\
\hline Distance & Santana MPA & Pau-Brasil MPA & Arraial MPA & Cagarras MPA & Cairuçu MPA \\
\hline $0-40 \mathrm{~km}$ & 4 & & & 11 & 4 \\
\hline 40-70 km & 1 & 4 & 4 & & \\
\hline $70-100 \mathrm{~km}$ & 9 & 7 & 17 & & \\
\hline Total & 14 & 11 & 21 & 11 & 4 \\
\hline
\end{tabular}

in this category (24 platforms and drill ships). However, Cagarras MPA had more platforms and drill ships in the shorter distance range (between 0-40 km) and consequently this MPA was the first in the ranking of the non-anchored factor. Cairuçu, which had the higher values in proximity, available substrate and similarity in this section, was the MPA that had the lower number of platforms and drill ships. However, these few vessels traveled very close to this area (Table IV). Table II shows the values for the nonanchored oil platforms section.

\section{Anchored Oil Platforms and Drill Ships}

Forty-one platforms and drill ships were classified as anchored for Rio de Janeiro State. Arraial do Cabo was the MPA that had more anchored platforms and drill ships up to $100 \mathrm{~km}$ from the coast. Following the similar results from the previous section, Cagarras MPA presented the highest number of platforms anchored at the closer distance (Table IV). In fact, all platforms and drill ships that anchored in the analyzed area of Cagarras MPA, anchored at a distance between 0-40 km, which also justifies why this MPA is first in the anchored factor ranking. The vessel that remained anchored for more time during the two years analyzed in this work was the oil platform Peregrino, anchored at Arraial do Cabo MPA and Pau-Brasil MPA for 630 days in the 70-100 km range. In contrast, the vessel that remained anchored for the shortest period of time was the platform Alpha Star, that anchored for 5 days in the $0-40 \mathrm{~km}$ range of the Cagarras MPA and in the 70-100 km range of the Arraial do Cabo MPA. All the platforms and drill ships recorded in the Rio de Janeiro State coastal area and the number of days anchored at each analyzed distance for all studied MPAs are shown in Supplementary Material - Table SI. Cairuçu MPA had the lowest number of anchored platforms and drill ships, but all the vessels located in the region, anchored in the 0-40 km range. Table II shows the scores for the anchored platforms.

\section{DISCUSSION}

We considered that this method showed good results. As each risk factor can be analyzed separately, it is possible to establish whether a 
region has more risk of sun coral introduction by natural dispersion or by vectors.

The GloBallast protocol was developed to assess the risk of invasion in a particular port considering several ports around the world as sources of ballast water. In the present protocol we assess the risk of several locations (MPAs) that can be contaminated by one location (donor area) or by vectors (platforms and drill ships). This is an inverse path and it required some adaptations.

Some studies have been done in an attempt to prevent new bioinvasions by hull fouling around the world (Johnson et al. 2001, Gollasch 2002, Floerl et al. 2005, Ashton et al. 2006, Acosta and Forrest 2009, Keller et al. 2011, Sylvester et al. 2011, Seebens et al. 2013) but none of them specifically take into account oil platforms and drill ships. Tracking the movement of these vessels together with other factors, this work proposes a protocol to analyze the risk of sun coral invasion in Marine Protected Areas.

There are three approaches in risk assessment: based on species level, based on pathway level or based on the vectors (Campbell 2009). Usually, risk assessments based on the vectors, like this work, are focused on specific vectors of the target species (Ashton et al. 2006, Davidson et al. 2008, Acosta \& Forrest 2009, Sylvester et al. 2011, Belz et al. 2012). Our focus was on oil platforms and drill ships, the main vectors of sun corals in Brazil.

The two species of sun coral Tubastraea coccinea and Tubastraea tagusensis were recorded in all MPAs analyzed in this study (Creed at al. 2017a). The presence of the sun coral in the Santana Archipelago was verified by the Sun Coral Project (unpublished data). In fact, all MPAs with rocky shores in Rio de Janeiro state appear to be infected with sun corals. After the introduction of a species, it is the secondary dispersal that will determine the level of any ecological and economic impact of a bioinvasion (Lodge et al. 1998). The control of the species is very important to decrease propagule pressure and to reduce the dispersal (Creed et al. 2017b). Also, it is important to prevent subsequent introductions inside regions that are already infested with sun coral, to conserve the biodiversity that remains. Even efforts that only slow spread can provide the time needed to assess potential impacts and, if necessary, develop additional control strategies (Johnson et al. 2001). Modeling the invasive potential of Tubastraea coccinea in the southwest Atlantic, Riul et al. (2013), show that the climatically suitable environment for $T$. coccinea spans from the north down to the south of Brazil. These results reinforce the importance of conducting risk analysis to help prevent primary and secondary sun coral introductions on the Brazilian coast.

Propagule pressure, which is the quantity of larvae that arrive into an area, is an important factor for the risk assessment. The Tubastraea genus has a reproductive strategy that leads to small scale dispersal (Glynn et al. 2008). The higher propagule pressure occurs in the first meters and tends to be lower at greater distances. Recently, this process was also cited by Santos et al. (2019), who studied the range expansion of the sun coral colonies. This supports why we used exponential weights for calculating the different distances for vectors and donor area. However, while new studies with Tubastraea spp. larvae were not conducted, we cannot be sure about their dispersal distance. As our method was designed in compartments, when information about the sun coral larvae is available, small adjustments can be easily done. We applied an exponential scale for the distances between the donor area and the analyzed MPA and also between the distance from the vessels and the MPAs. The expansion 
rate for Tubastraea was estimated at $2.1 \mathrm{~km} . \mathrm{yr}^{-1}$ (Silva et al. 2014). Tubastraea larvae can live for 18 days in an aquarium without settling (Paula et al. 2014); however, they usually settle close to the mother colony (Creed et al. 2017a). This behavior can explain why sun coral larvae were never recorded in ballast water. Sun coral colonies encrusted on moving platforms (or drill ships) may release larvae when they get closer to the coast. As a consequence, the larvae could not settle close to the mother colony. In this case, the larvae would be carried by the currents to the coast. For this reason, the available substrate was included in the risk analysis. If larvae arrive in a place with no hard substrate, they will probably die before settling. Considering the range of dispersal of sun coral larvae, the platforms and drill ships were classified at different distances from the coast. There is a lack of information about the distance that the sun coral larvae could be carried by the currents until settlement, and this information was needed to complete the risk analysis. Zilberberg et al. (2016) state that coral larvae of the genus Mussismilia, which settle within 10 days after release, can reach 100 kilometers before settlement. In this work this information was used as a proxy to set the distance in the risk analysis. The information about the larvae dispersion of the genus Mussismilia given by Zilberberg et al. (2016) was made for the Bahia state coast. The distance that the larvae could reach depends on the currents and wind. Yet, for larvae to reach a $100 \mathrm{~km}$ distance, all the environmental conditions should be favorable. For this reason, the majority of the larvae should settle before reaching $100 \mathrm{~km}$ distance. However, the risk analysis should consider the maximum distance that is possible for the larvae to reach. It is certain that a larvae dispersal model for the Rio de Janeiro coast would improve the method, making it more accurate-
In laboratory experiments, the work of Mizrahi et al. (2014) showed that the planulae of $T$. coccinea can undergo metamorphosis and form aggregate groups of polyps without settlement and these pelagic polyps can live longer than the planulae. This information is important to the risk analysis. However, without knowing the distance that the aggregate of polyps could reach, this information cannot be used in the analysis.

One important step of risk analysis studies (Gollasch 2002, Bartell \& Nair 2003, Keller et al. 2011, Seebens et al. 2013) includes the information about the point of origin of a vessel. There are two types of AIS data. The terrestrial AIS provide data about coastal traffic from receivers in the coast, so, there is a limited distance that the device can get a vessel position. The other is the satellite AIS, that can provide vessels traffic information around the world. However, as Seebens et al. (2013) state, the AIS devices had not been installed on all ships and ports until 2008. Some platforms have been in operation for more than thirty years, much longer than the existence of the AIS technology. So, some vectors were built before this technology exists, then, it could be infected with sun coral before the AIS technology arrive. For this reason we used the terrestrial AIS and assume that all vectors are infected with sun coral. Beyond that, the focus of risk analysis was in the main vectors of sun corals in Brazil, oil platforms and drill ships. With the AIS technology it is possible to gather this information. However, an oil platform or drill ship can remain anchored for years and it is very difficult to know the moment that the vessel started to move, which makes it difficult to get the entire period of the platform movement. AIS technology is not that old, maybe it is possible to acquire data from ten years ago.

Hayes \& Hewitt (1998) in the Risk Assessment Framework for Ballast Water Introductions 
suggested some steps to do this assessment. One of the steps is to identify the original port of the vessel. Platforms and drill ships are the main vectors of the sun coral introduction in Brazil (Creed et al. 2017a) and do not know the origin of all the platforms. In this work, it was assumed that all oil platforms were contaminated with sun coral. As some data are not yet available in the literature, as for example the distance the larvae of sun corals could reach or the real quantity of vectors that are infested with sun corals, this information had to be extrapolated. These extrapolations must be done in order to protect biodiversity. It is a conservative or precautionary analysis, but it is needed if we want to prevent new introductions when the origin of the platform is not known.

Another step proposed by Hayes \& Hewitt (1998), is to conduct a port or a bioregion match. The present work does not include ports as donors. Tamoios MPA was analyzed as a donor region, since it was the most infested, so the environmental similarity analysis was performed between the Tamoios MPA and the other studied MPAs. Some studies take into account only salinity and temperature (Keller et al. 2011, Gollasch 2002) in the similarity analysis, however, the greater the number of environmental factors used in the analysis, a more robust result will be reached.

The study of Davidson et al. (2008), verified the hull fouling on two abandoned ships in the Ready Reserve Fleet. These ships can be anchored for decades. They analyzed the hulls from the point that the ship was anchored up to the point that these ships were transported for dismantling and recycling at a relatively low speed. They found that 22 species were encrusted on the hull at the start of the transport. The interesting finding was that at the end of the transport, nine species were still encrusted on the hull and that new species settled during the transport. The longer the time that a vessel spent anchored in a port, the greater is the number of the fouling species found on the hull (Sylvester et al. 2011), justifying the inclusion of the factor "anchored time" as part of the model suggested by these authors. These examples could be compared with the oil platforms, which may also remain anchored for years and when they move, they take along species that have a chance to be introduced in new environments. As the anchored time can increase the quantity of fouling species, we include this data in the protocol. In fact, this situation could be aggravated over time when the older oil wells run out of oil and the older platforms are removed from the coast, without previous treatment (Oigman-Pszczol et al. 2017).

Cairuçu is the MPA that needs more attention at this moment in relation to factors that are not linked to the platforms and drill ships. Only a few vessels entered Itha Grande Bay during the analyzed period, which means that the actions that need to be taken to avoid the dispersal inside this MPA are to increase sun coral management and monitoring. In this case, vector movements were not of great influence. For this MPA the sun coral was already recorded, however, many islands and rocky shores are not yet infested with sun coral. In order to protect the biodiversity at these sites, mitigation measures are needed. This MPA is the closest to the donor area and has the highest amount of available substrate for the settlement of Tubastraea. These factors were those that most contributed to the risk of invasion in the Cairuçu MPA.

Besides Cairuçu MPA, Cagarras was the only MPA that was located at a distance from the donor region which influences the analysis. However, this distance was in the farthest range analyzed (70-100 km). Cagarras is the MPA that had more anchored and nonanchored oil platforms and drill ships at the 
closest analyzed range. The platforms enter and leave the Guanabara Bay, usually for repair and maintenance, passing at less than $3 \mathrm{~km}$ from the Cagarras MPA which contributes to it being the second area that needs more attention. In the case of this MPA monitoring of the vectors is essential to prevent further invasions. Cagarras MPA supports a high biodiversity such as that observed in other systems of the Mata Atlântica biome, although it is close to Rio de Janeiro, one of the most populated cities of Brazil. It protects a high diversity of fauna and flora (Rangel et al. 2007). Sun coral monitoring and management at these islands must be a priority in the near future as a conservation strategy of this rich ecosystem.

The other MPAs do not have a high available substrate value or a high proximity score. In the area of Arraial do Cabo MPA, Pau-Brasil MPA and Santana MPA, which are relatively close to each other, the presence of platforms and drill ships were the factors that had more weight in the risk analysis. Santana MPA is located in the Campos Basin, which is an oil field where dozens of platforms and drill ships are anchored or in movement. Analyzing the movements of the platforms and drill ships, we found that some were anchored at approximately $1 \mathrm{~km}$ from the Santana archipelago. These structures often leave the Campos Basin located in the north of Rio de Janeiro State, towards the south of the State. During these movements, the platforms and drill ships passed close to the Pau-Brasil MPA and the Arraial do Cabo MPA. Like Cagarras MPA, these MPAs are more influenced by the vectors and not by the proximity with the donor area and likewise, monitoring of the vectors is essential.

It should be clear that this protocol is relative to Rio de Janeiro State. However, this method allows the insertion of new data from other MPAs. This protocol gives separate information about each factor of the risk analysis. If we look at each one separately, we can propose different actions to reduce risk based on each analyzed MPA. One course of action could be to invest in sun coral monitoring, like Cairuçu MPA, that has higher available substrate for colonization by sun corals and is the closest one to the donor MPA. Another course of action is investment in monitoring the platforms and drill ships, like all the other analyzed MPAs.

We also consider that this protocol could be used for other fouling organisms that are invasive or have an invasive potential for other countries. In fact, Tubastraea coccinea has also been observed recently on natural banks within the northern Gulf of Mexico (GoM), and a model to estimate the expansion range was developed (Derouen et al. 2020). Besides identifying likely areas of potential range expansion and the environmental determining factors of invasion (Derouen et al. 2020) a protocol which also considers the proximity of vectors would be useful to prevent new invasions in areas that are considered important to the conservation of biodiversity and could increase the chances of preserving important species.

We recommend that all MPAs analyzed carry out substrate monitoring. We also recommend the monitoring of the vectors to avoid new introductions mainly for the Cagarras MPA, Santana MPA and Pau-Brasil MPA, that had higher scores of the vector factors. We advise the application of this protocol to analyze the relative risk for the entire Brazilian coast, in order to prevent new invasions. The next step is to perform the risk analysis for the entire Brazilian coast. There are on the coast, ports and shipwrecks that have sun corals registered and are not located inside any MPA. In order to improve the risk analysis, these ports and shipwrecks should be used as donor areas. 
This protocol can also be used by the decision-makers for a better management of the Marine Protected Areas, as it can aid in the process of evaluating a management strategy to determine what components of the invasion process are more susceptible to control.

\section{Acknowledgments}

We thank Drs. Graeme Inglis and Joel Creed for their valuable comments on the draft of this manuscript and risk analysis protocol respectively. We also would like to thank the Integrated Maritime Safety Centre (CISMAR Centro Integrado de Segurança Marítima) of the Brazilian Navy which provided the movement data from platforms and drill ships in order to complete the risk analysis. The authors are indebted to Rafael Bendayan de Moura for the edition of Figure 1 and to Thomas Sprengers for the English revision. This study is part of the Sun-Coral Project and was funded by the Commitment to Conduct Adjustment Agreement signed by Chevron Brasil with the Brazilian Federal Prosecution Service (Ministério Público Federal), with implementation by the Brazilian Biodiversity Fund (FUNBIO) and also by the Fundação Carlos Chagas Filho de Amparo à Pesquisa do Estado do Rio de Janeiro (FAPERJ Proc. No. E-26/010.003031/2014 - PensaRio). This article is no. 44 from the Projeto Coral-Sol.

\section{REFERENCES}

ACOSTA H \& FORREST BM. 2009. The spread of marine non-indigenous species via recreational boating: A conceptual model for risk assessment based on fault tree analysis. Ecol Model 220(13): 1586-1598.

ANDERSEN MC, ADAMS H, HOPE B \& POWELL M. 2004. Risk Assessment for Invasive Species. Risk Anal 24: 787-793.

ASHTON G, BOOS K, SHUCKSMITH R \& COOK E. 2006. Risk assessment of hull fouling as a vector for marine nonnatives in Scotland. Aquat Invasions 1(4): 214-218.

BARTELL SM \& NAIR SK. 2003. Establishment Risk for Invasive Species. Risk Anal 24: 833-845.

BELZ CE, DARRIGRAN G, NETTO OSM, BOEGER WA \& JUNIOR PJR. 2012. Analysis of Four Dispersion Vectors in Inland Waters: The Case of the Invading Bivalves in South America. J Shellfish Res 31(3): 777-784.

CAMPBELL ML. 2009. An Overview of Risk Assessment in a Marine Biosecurity Context. In: Rilov G \& Crooks JA (Eds),
Biological Invasions in Marine Ecosystems: Ecological, Management, and Geographic Perspectives. Springer, Heidelberg, Germany, p. 353-370.

CAPEL KCC, CREED J, KITAHARA MV, CHEN CA \& ZILBERBERG C. 2019. Multiple introductions and secondary dispersion of Tubastraea spp. in the Southwestern Atlantic. Sci Rep 13978.

CASTRO CB \& PIRES DO. 2001. Brazilian coral reefs: What we already know and what is still missing. Bull Mar Sci 69: 357-371.

CLARKE C, HILLIARD R, JUNQUEIRA AOR, LEAL NETO AC, POLGLAZE J \& RAAYMAKERS S. 2004. Ballast Water Risk Assessment, Port of Sepetiba, Federal Republic of Brazil, 2003: Final Report. GloBallast Monograph Series No. 14. IMO London.

CONABIO. 2018. Comissão Nacional de Biodiversidade Estratégia Nacional para Espécies Exóticas Invasoras. Resolution 7. (acessed June 2018).

COELHO-SOUZA SA, LÓPEZ MS, GUIMARÃES JRR, COUTINHO R \& CANDELLA RN. 2012. Biophysical interactions in the Cabo Frio upwelling system, Southeastern Brazil. Braz J Oceanogr 60: 353-365.

CREED JC ET AL. 2017a. The invasion of the azooxanthellate coral Tubastraea (Scleractinia: Dendrophylliidae) through the world: history, pathways and vectors. Biol Invasions 19: 283-305.

CREED JC, JUNQUEIRA AOR, FLEURY BG, MANTELATTO MC \& OIGMAN-PSZCZOL SS. 2017b. The Sun-Coral Project: the first social-environmental initiative to manage the biological invasion of Tubastraea spp. in Brazil. Manag Biol Invasion 8: 181-195.

CREED JC, PIRES DO \& FIGUEIREDO MAO. 2007. Biodiversidade Marinha da Baía da Ilha Grande. Brasília: Ministério do Meio Ambiente, Brasil, 416 p.

DAVIDSON IC, MCCANN LD, FOFONOFF PW, SYTSMA MD \& RUIZ GM. 2008. The potential for hull-mediated species transfers by obsolete ships on their final voyages. Divers Distrib 14: 518-529.

DE PAULA AF, FLEURY BG, LAGES BG \& CREED JC. 2017. Experimental evaluation of the effects of management of invasive corals on native communities. Mar Ecol Prog Ser 572: 141-154.

DEROUEN ZC, PETERSON MR, WANG H \& GRANT WE. 2020. Determinants of Tubastraea coccinea invasion and likelihood of further expansion in the northern Gulf of Mexico. Mar Biodivers 50: 101. 
DHN. 2017. Departamento de Hidrografia e Navegação. https://www.marinha.mil.br/dhn/ (accessed November 2017).

FARRAPEIRA CMR, TENÓRIO DO \& AMARAL FD. 2011. Vessel biofouling as an inadvertent vector of benthic invertebrates occurring in Brazil. Mar Pollut Bull 62: 832-839.

FERREIRA CEL, GONÇALVES JEA \& COUTINHO R. 2006. Ship hulls and oil platforms as potential vectors to marine species introduction. J Coastal Res 39: 1340-1345.

FIGUEROA DF, MCCLURE A, FIGUEROA NJ \& HICKS DW. 2019. Hiding in plain sight: invasive coral Tubastraea tagusensis (Scleractinia: Hexacoralia) in Gulf of Mexico. Coral Reefs 38: 395-403.

FLOERL O, INGLIS GJ \& HAYDEN BJ. 2005. A Risk-Based Predictive Tool to Prevent Accidental Introductions of Nonindigenous Marine Species. Environ Manage 35(6): 765-778.

GENTILE JH, HARWELL MA, VAN DER SCHALIE W, NORTON S \& RODIER D. 1993. Ecological risk assessment: a scientific perspective. J Hazard Mater 35: 241-253.

GLYNN PW, COLLEY SB, MATÉ JL, CORTÉS J, GUZMAN HM, BAILEY RL, FEINGOLD JS \& ENOCHS IC. 2008. Reproductive ecology of the azooxanthellate coral Tubastraea coccinea in the Equatorial Eastern Pacific: Part V. Dendrophylliidae. Mar Biol 153: 529-544.

GOLLASCH S. 2002. The importance of ship hull fouling as a vector of species introductions into the North Sea. Biofouling 18: 105-121.

HAYES KR \& HEWITT CL. 1998. Risk Assessment Framework for Ballast Water Introductions. CRIMP Technical Report $N^{0}$ 14, CSIRO Division of Marine Research, Hobart, Australia.

HEWITT CL, CAMPBELL ML, THRESHER RE \& MARTIN JB. 1999. Marine biological invasions of Port Philip Bay, Victoria. CSIRO. Centre for research on Introduced Marine Pests, Tech Rep No 20, 344 p.

INMET. 2017. Instituto Nacional de Meteorologia. www. inmet.gov.br (accessed November 2017).

JOHNSON LE, RICCIARDI A \& CARLTON JT. 2001. Overland Dispersal of Aquatic Invasive Species: A Risk Assessment of Transient Recreational Boating. Ecol Appl 11: 1789-1899.

JOHNSON RA \& WICHERN DW. 1988. Applied Multivariate Analysis. $2^{\text {nd }}$ ed., John Wiley \& Sons Inc., New York.

J RGENSEN SE \& BENDORICCHIO G. 2001. FUNDAMENTALS OF Ecological Modelling. $3^{\text {rd }}$ ed., Elsevier, Oxford, United Kingdom, 530 p.
KAPLAN S \& GARRICK BJ. 1981. On the quantitative definition of risk. Risk Anal 1: 11-27.

KELLER RP, DRAKE JM, DREW MB \& LODGE DM. 2011. Linking environmental conditions and ship movements to estimate invasive species transport across global shipping network. Divers Distrib 17: 93-102.

LAGES B, FLEURY B, HOVELL AC, REZENDE C, PINTO A \& CREED J. 2012. Proximity to competitors changes secondary meta bolites of non-indigenous cup corals, Tubastraea spp., in the southwest Atlantic. Mar Biol 159: 1551-1559.

LAGES BG, FLEURY BG, MENEGOLA C \& CREED JC. 2011. Change in tropical rocky shore communities due to an alien coral invasion. Mar Ecol Prog Ser 438: 85-96.

LAGES BG, FLEURY BG, PINTO AC \& CREED JC. 2010. Chemical defenses against generalist fish predators and fouling organisms in two invasive ahermatypic corals in the genus Tubastraea. Mar Ecol 31: 473-482.

LOCKWOOD JL, HOOPES MF \& MARCHETTI MP. 2007. Invasion Ecology. Blackwell Publishing Ltd, Oxford.

LODGE DM, STEIN KM, BROWN KM, COVICH AP, BRONMARK C, GGARVEY JE \& KLOSIEWSKI SP. 1998. Predicting impact of freshwater exotic species on native biodiversity: challenges in spatial scaling. Aust J Ecol 23: 53-67.

LÓPEZ C, CLEMENTE S, MORENO S, OCAÑA O, HERRERA R, MORO L, MONTERROSO O, RODRÍGUEZ A \& BRITO A. 2019. Invasive Tubastraea spp. and Oculina patagônica and other introduced scleractinians corals in the Santa Cruz de Tenerife (Canary Islands) harbor: Ecology and potential risks. Reg Stud Mar Sci 29: 100713.

MACK RN, SIMBERLOFF D, LONSDALE WM, EVANS H, CLOUT M \& BAZZAZ FA. 2000. Biotic invasions: causes, epidemiology, global consequences, and control. Ecol Appl 10: 689-710.

MANTELATTO MC, PÓVOA AA, SKINNER LF, ARAUJO FV \& CREED JC. 2020. Marine litter and wood debris as habitat and vector for the range expansion of invasive corals (Tubastraea spp.). Mar Pollut Bull 160: 111659.

MANTELATTO MC \& CREED JC. 2015. Non-indigenous sun corals invade mussel beds in Brazil. Mar Biodivers 45: 605-606.

MARCHETTI MP, MOYLE PB \& LEVINE R. 2004. Alien fishes in California watersheds: Characteristics of successful and failed invaders. Ecol Appl 14: 587-596.

MIRANDA RJ, TAGLIAFICO A, KELAHER BP, MARIANO-NETO E \& BARROS F. 2018. Impact of invasive corals Tubastraea spp. on native coral recruitment. Mar Environ Res. 138: 19-27. 
MIRANDA RJ, CRUZ ICS \& BARROS F. 2016a. Effects of the alien coral Tubastraea tagusensis on native coral. Mar Biol 163: 1-12.

MIRANDA RJ, COSTA Y, LORDERS FL, JOSÉ DE ANCHIETA C \& BARROS F. 2016b. New records of the alien cup-corals (Tubastraea spp.) within estuarine and reef systems in Todos os Santos Bay Southwestern Atlantic. Mar Biodivers Rec 9: 35.

MIZRAHI D, NAVARRETE as \& FLORES AAV. 2014. Groups travel further: pelagic metamorphosis and polyp clustering allow higher dispersal potential in sun coral propagules. Coral Reefs 33: 443-448.

MOLNAR JM, GAMBOA RL, REVENGA C \& SPALDING MD. 2008. Assessing the global threat of invasive species to marine biodiversity. Front Ecol Environ 6: 485-492.

NOAA. 2017. National Oceanic and Atmospheric Administration. https://www.nnvl.noaa.gov/view/ globaldata.html (accessed November 2017).

OIGMAN-PSZCZOL SS, CREED J, FLEURY B, MANTELATTO MC, CAPEL KCC, MEIRELES C, CABRAL D, MASI B \& JUNQUEIRA A. 2017. O controle da invasão do coral-sol no Brasil não é uma causa perdida. Cien Cult 69: 56-59.

OLENIN S ET AL. 2011. Recommendations on methods for the detection and control of biological pollution in marine coastal Waters. Mar Pollut Bull 62: 2598-2604.

PAULA AF, PIRES DO \& CREED JC. 2014. Reproductive strategies of two invasive sun corals (Tubastraea spp.) in the southwestern Atlantic. J Mar Biol Assoc UK 94: 481-492.

RANGEL CA, CHAVES LCT \& MONTEIRO-NETO C. 2007. Baseline Assessment of the Reef Fish Assemblage from Cagarras Archipelago, Rio de Janeiro, Southeastern Brazil. Braz J Oceanogr 55: 7-17.

RIUL P, TARGINO CH, JUNIOR LAC, CREED JC, HORTA PA \& COSTA GC. 2013. Invasive potential of the coral Tubastraea coccinea in the southwest Atlantic. Mar Ecol Prog Ser 480: 73-81.

SAMMARCO PW, ATCHISON AD \& BOLAND GS. 2004. Expansion of coral communities within the Northern Gulf of Mexico via offshore oil and gas platforms. Mar Ecol Prog Ser 280: 129-143.

SAMPAIO CLS, MIRANDA RJ, MAIA-NOGUEIRA R \& NUNES JCC. 2012. New occurrences of the nonindigenous orange cup corals Tubastraea coccinea and T. tagusensis (Scleractinia: Dendrophylliidae) in Southwestern Atlantic. Check List 8: 528-530.

SANTOS HS, SILVA FGC, MASI BP, FLEURY BG \& CREED JC. 2019. Environmental matching used to predict range expansion of two invasive corals (Tubastraea spp.). Mar Pollut Bull 145: 587-594.

SANTOS LAH, RIBEIRO FV \& CREED JC. 2013. Antagonism between invasive pest corals Tubastraea spp. And the native reef-builder Mussismilia hispida in the southwest Atlantic. J Exp Mar Biol Ecol 449: 69-76.

SEEBENS H, GASTNER MT \& BLASIUS B. 2013. The risk of marine bioinvasion caused by global shipping. Ecol Lett 16: 782-790.

SILVA R, VINAGRE C, KITAHARA MV, ACORSI IV, MIZRAHI D \& FLORES AA. 2019. Sun coral invasion of shallow rocky reefs: effects on mobile invertebrate assemblages in Southeastern Brazil. Biol Inv. 21: 1339-1350.

SILVA AG, PAULA AF, FLEURY BG \& CREED JC. 2014. Eleven years of range expansion of two invasive corals (Tubastraea coccinea and $T$. tagusensis) through the southwest Atlantic (Brazil). Estuar Coast Shelf Sci 141: 8-16.

SYLVESTER F, KALACI O, LEUNG B, LACOURSIERE-ROUSSEL A, MURRAY CC, CHOI FM, BRAVO MA, THERRIAULT TW \& MACLSAAC HJ. 2011. Hull fouling as an invasion vector: can simple models explain a complex problem? J Appl Ecol 48: 415-423.

TREUT HL. 1999. Large scale climate modelling and its application to the problem of climate sensitivity. In: Blasco F \& Weill A (Eds), Advances in Environmental and Ecological Modelling. Elsevier, Paris, France, p. 3-16.

WELLS JW. 1982. Notes on Indo-Pacific Scleractinian Corals. Part 9. New Corals from the Galápago Islands. Pac Sci 36(2): 211-219.

ZILBERBERG C, ABRANTES DP, MARQUES JA, MACHADO LF \& MARANGONI LFB. 2016. Conhecendo os Recifes Brasileiros: Rede de Pesquisas Coral Vivo. Série Livros Museu Nacional, Rio de Janeiro.

\section{SUPPLEMENTARY MATERIAL}

Table SI. Platforms and drill ships that were recorded from the coast until $100 \mathrm{~km}$ in the Rio de Janeiro State and the number of days that the vessels that anchored in the analyzed MPAs remained in each analyzed distance.

\section{How to cite}

COUTO TDTC, OMENA EP, OIGMAN-PSZCZOL SS \& JUNQUEIRA AOR. 2021. A Method to Assess the Risk of Sun Coral Invasion in Marine Protected Areas. An Acad Bras Cienc 93: e20200583. DOI 10.1590/00013765202120200583. 
Manuscript received on April 18, 2020;

accepted for publication on February 2, 2021

THIAGO D. T. C. COUTO ${ }^{1}$

https://orcid.org/0000-0001-8671-2583

\section{ELIANNE P. OMENA ${ }^{1}$}

https://orcid.org/0000-0003-1546-4572

\section{SIMONE S. OIGMAN-PSZCZOL ${ }^{1}$}

https://orcid.org/0000-0002-9340-8384

ANDREA O.R. JUNQUEIRA, ${ }^{1,2}$

https://orcid.org/0000-0002-3386-2454

${ }^{1}$ Instituto Brasileiro de Biodiversidade - BrBio, Associate

Researcher, Sun Coral Research, Technological Development and Innovation Network, Rua Senador Dantas, 20, Sala

1509, Centro, 20031-203 Rio de Janeiro, RJ, Brazil

${ }^{2}$ Universidade Federal do Rio de Janeiro, Instituto

de Biologia, Avenida Carlos Chagas Filho, 373, Itha

do Fundão, 21941-913 Rio de Janeiro, RJ, Brazil

Correspondence to: Thiago Drumond Teixeira Correia Couto

E-mail:thiago.couto@brbio.org.br

\section{Author Contributions}

T. Couto and A. Junqueira designed the study and the method. T. Couto and A. Junqueira analyzed the data and interpreted the results with input from all authors. T. Couto wrote the original draft. A. Junqueira, E. Omena and S. Oigman-Pszczol participated of the review and editing. All authors approved the final version of the manuscript.

\section{(cc) BY}

